\title{
NEW INSIGHTS INTO SOUTHERN OCEAN PHYSICAL AND BIOLOGICAL PROCESSES REVEALED BY INSTRUMENTED ELEPHANT SEALS.
}

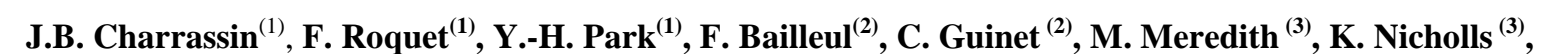
S. Thorpe ${ }^{(3)}$, B. McDonald ${ }^{(4)}$, D.P. Costa ${ }^{(4)}$, I. Tremblay $^{(5)}$, M. Goebel ${ }^{(6)}$, M. Muelbert ${ }^{(7)}$, M.N. Bester ${ }^{(8)}$, J. Plötz ${ }^{(9)}$, H. Bornemann ${ }^{(9)}$, R. Timmermann ${ }^{(9)}$, M. Hindell ${ }^{(10)}$, A. Meijers ${ }^{(11)}$, R.C. Coleman ${ }^{(11)}$, I.C. Field ${ }^{(12)}$, C.M. McMahon ${ }^{(13)}$, S.R. Rintoul ${ }^{(14)}$, S. Sokolov ${ }^{(14)}$, L. Boehme ${ }^{(15)}$, P. Lovell $^{(15)}$, M.A. Fedak ${ }^{(15)}$, M. Biuw ${ }^{(16)}$, O.A. Nost ${ }^{(16)}$, C. Lydersen ${ }^{(16)}$, K.M. Kovacs ${ }^{(16)}$

(1) LOCEAN (Laboratoire d'Océanographie et du Climat: Expérimentations et approches numériques)/Muséum National d'Histoire Naturelle, 43 rue Cuvier, 75231 Paris Cedex 05, France,

Email: jbc@mnhn.fr; roquet@mnhn.fr; yhpark@mnhn.fr

(2) Centre d'Études Biologiques de Chizé, CNRS (Centre National de la Recherche Scientifique), BP 14, F-79360 Villiers-en-Bois, France, Email: bailleul@cebc.cnrs.fr; guinet@cebc.cnrs.fr

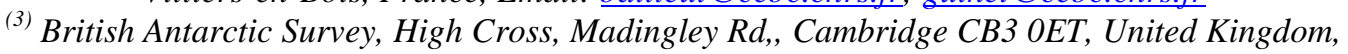
Email: mmm@bas.ac.uk; kwni@bas.ac.uk; seth@bas.ac.uk

(4) Center for Ocean Health, Institute of Marine Sciences, Long Marine Lab, University of California, 100 Shaffer Rd., Santa Cruz, CA 95060, USA, Email: mcdonald@biology.ucsc.edu; costa@ucsc.edu

${ }^{(5)}$ Centre de Recherche Halieutique Méditerranéenne et Tropicale, IRD Avenue Jean Monnet, BP 171, 34203 Sète Cedex, France, Email: yann.tremblay@ird.fr

${ }^{(6)}$ Antarctic Ecosystem Research Division/NOAA (National Oceanic and Atmospheric Administration), National Marine Fisheries Service, 8604 La Jolla Shores Drive, La Jolla, CA 92037-1508, USA, Email: Mike.Goebel@noaa.gov

(7) PPGOB (Programa de Pós-graduação em Oceanografia Biológica) - Instituto de Oceanografia, Universidade Federal do Rio Grande, Caixa Postal 474, 96201-900 Rio Grande RS Brasil, Email: Monica.Muelbert@furg.br

${ }^{(8)}$ Mammal Research Institute, Department of Zoology \& Entomology, School of Biological Sciences, University of Pretoria, Pretoria 0002, South-Africa, Email: mnbester@zoology.up.ac.za

${ }^{(9)}$ Alfred Wegener Institute, Columbusstrasse, D-27568 Bremerhaven, Germany, Email: Joachim.Ploetz@awi.de;

${ }^{(9)}$ Alfred Wegener Institute for Polar and Marine Research, P.O. Box 1201 61, 27515 Bremerhaven, Germany, Email: hbornemann@awi-bremerhaven.de

(9) Alfred Wegener Institute, Bussestrasse 24, D-27570 Bremerhaven, Germany, Email: Ralph.Timmermann@awi.de

${ }^{(10)}$ Antarctic Wildlife Research Unit, University of Tasmania, PO Box 252-05, Hobart, TAS 7001, Australia, Email: Mark.Hindell@utas.edu.au

${ }^{(11)}$ Center for Marine Science, University of Tasmania, Private Bag 78, Hobart, TAS 7001, Australia, Email:ameijers@utas.edu.au; richard.coleman@utas.edu.au

${ }^{(12)}$ Marine Mammal Research Group, Graduate School of the Environment, Macquarie University Sydney, NSW 2109, Australia, Email: ifield@science.mq.edu.au

(13) School for Environmental Research, Charles Darwin University, Darwin NT 0909, Australia, Email: clive.mcmahon@cdu.edu.au

(14) CSIRO (Commonwealth Scientific and Industrial Research Organisation) Wealth from Oceans National Research Flagship and Antarctic Climate and Ecosystems Cooperative Research Centre, Hobart, TAS 7001, Australia, Email: Steve.Rintoul@csiro.au; Serguei.Sokolov@csiro.au

${ }^{(15)}$ Sea Mammal Research Unit, Gatty Marine Laboratory, University of St Andrews, St Andrews, Fife KY16 8LB, United Kingdom, Email: lb284@st-andrews.ac.uk; p.lovell@sea-mammal-research-unit.st-andrews.ac.uk; maf3@st-andrews.ac.uk

${ }^{(16)}$ Norwegian Polar Institute, Polar Environmental Centre, Fram Centre, Hjalmar Johansens, gt. 14, NO-9296 Troms $\phi$, Norway, Email: martin.biuw@npolar.no; ole.anders.nost@npolar.no; christian.lydersen@npolar.no; kit.kovacs@npolar.no

\begin{abstract}
In recent years, the international "Southern Elephant seals as Oceanographic Samplers" (SEaOS) project has deployed miniaturized conductivity-temperature-depth satellite-relayed data loggers (CTD-SRDL) on elephant seals 1) to study their winter foraging ecology in relation to oceanographic conditions, and 2) to collect hydrographic data from polar regions, which are
\end{abstract}

otherwise sparsely sampled. We summarize here the main results that have been published in both science components since 2003/2004. Instrumented southern elephant seals visit different regions within the Southern Ocean (frontal zones, continental shelf, and/or ice covered areas) and forage in a variety of different water masses (e.g. Circumpolar Deep Water upwelling regions, High Salinity Shelf Water), depending on their geographic distribution. Adult females and juvenile 
males from Kerguelen Is. forage pelagically in frontal zones of the Southern Indian Ocean, while adult males forage benthically over the Kerguelen Plateau and the Antarctic Continental Shelf, with the two groups feeding at different trophic levels as shown by stable isotopes analysis. Oceanographic studies using the data collected from the seals have, to date, concentrated on circumpolar and regional studies of the Antarctic Circumpolar Current (ACC) circulation. The temperature and salinity profiles documented by elephant seals at high latitudes, including below sea ice, have permitted quasi-circumpolar mapping of the southernmost fronts of the ACC. By merging conventional data and the high temporal and spatial resolution data collected by seal-borne SRDLs, it has been possible to describe precisely 1) the large-scale features of the ACC in the South Atlantic and its variability; 2) the circulation pattern over the Kerguelen plateau, revealing that the poorly known Fawn Trough concentrates an important proportion of the ACC flow in that region. Seals that foraged in ice covered areas have made eulerian time series available that have allowed for the estimation of sea ice formation rates, a parameter that is otherwise difficult to obtain, while also providing a unique description of the wintertime ocean circulation over the central Weddell Sea continental shelf. Finally, we present the first data collected by a newly-developed fluorescence sensor that has been embedded in the regular CTD-SRDL and deployed on elephant seals at Kerguelen. The fluorometer data obtained have offered the first synoptic view of the 3 dimensional distribution of temperature, salinity and fluorescence over a vast sector of the Southern Indian Ocean, allowing us to describe both vertical and horizontal variations in chlorophyll.

This paper will make a core contribution to the Plenary Sessions $2 \mathrm{C}, 3 \mathrm{~A}$ and $4 \mathrm{~A}$, and will be relevant to $2 \mathrm{~A}$ and 2B.

\section{INTERNATIONAL CONTEXT OF THE PROJECT}

The international "Southern Elephant seals as Oceanographic Samplers" (SEaOS) project started in the austral summer 2003/2004. Its goal was to deploy miniaturized conductivity-temperature-depth satelliterelayed data loggers (CTD-SRDL) on Southern elephant seals at a variety of colonies spread across the sub Antarctic to 1) study their winter foraging ecology in relation to oceanographic conditions, and 2) collect hydrographic data from otherwise sparsely sampled polar regions. Tags were deployed on elephant seals by France at Kerguelen $(n=46,2004-2007)$, the UK at South Georgia $(\mathrm{n}=21,2004-2005)$, Australia at Macquarie Island $(n=16,2004-2005)$, and the USA at South Shetland Islands (Antarctic Peninsula) $(\mathrm{n}=19$,
2005-2006). This work has been extended by the International Polar Year project MEOP (Marine Mammals Exploration of the Oceans Pole to Pole) that was launched in 2007, in which Norway, Brazil, and South Africa also deployed tags in the Southern Ocean on elephant seals. It is important to note that deployments on southern elephant seals have continued since 2006 at most SEaOS study sites, while new MEOP partners have undertaken deployments at additional sites, including Marion, Bouvet, and Elephant Islands, and Casey in Eastern Antarctica. The seal CTD projects have proven to be very successful. In the current summary we focus primarily on the results of published studies and submitted manuscripts, both on ecological and oceanographic aspects of the data reported by seal CTD-SRDLs, summarizing the main knowledge acquired in both domains. We will also present briefly the first data collected using a new sensor that integrates fluorescence measurements into the basic CTD-SRDL tag. All details on the CTD-SRDL manufactured by the Sea Mammal Research Unit (SMRU) in Scotland are provided in the companion CWP (Community White Paper) by [1], along with a general discussion of the concept of using seals as oceanographic samplers. Physical data quality, calibration and validation procedures of the data collected by CTD-SRDL are presented in a companion "additional contribution" to OceanObs'09 [2]. The seal calibrated dataset presented by these authors was produced with a temperature accuracy of order $0.02^{\circ} \mathrm{C}$ and a salinity accuracy of order 0.03 [3]. Similar projects in the international community include TOPP (Tagging of Pacific Predators) deploying CTD-SRDL tags on Northern Elephant seals (see [4]), and several studies on other marine mammal species.

\section{A GLOBAL ECOLOGICAL STUDY}

In order to understand the contrasting trends of the different southern elephant seals populations around the Southern Ocean [5], an unprecedented, simultaneous, circumpolar tagging effort has been conducted at four breeding localities [6]. The same type of instruments (CTD-SRDLs) was deployed on 85 elephant seals simultaneously at Kerguelen, South Georgia, Macquarie and the South Shetlands between January 2004 and April 2006. Instruments were deployed in January and February at the end of the annual moult, to document the pre-breeding winter foraging trip, a key part of the annual cycle of these seals. Data were transmitted for an average of $161 \pm 83$ days, with the longest data record (326 days) covering the entire winter migration and the subsequent summer trip of one female from South Georgia. Dive depth showed substantial diurnal differences that are likely related to the diurnal migrations of prey, and there was a trend for dives to be deeper in the northern parts of the Southern Ocean and 
shallower closer to the Antarctic continent. Average dive depth was around $300-500 \mathrm{~m}$, with a maximum at $1800 \mathrm{~m}$ [6]. The elephant seals explored three main habitats: the open ocean in the Polar Frontal Zone (most seals from South Georgia and South Shetland, and some seals from Kerguelen and Macquarie Is); the marginal sea ice zone (most animals from Macquarie Island); and the peri-Antarctic Continent (seals from Kerguelen and Macquarie, diving benthically). Using changes in drift rate measured during dives as a proxy of body condition (fatter seals tend to be more buoyant while leaner seals tend to sink), and CTD profiles obtained from the seals, the most favourable water masses in terms of foraging were identified. Circumpolar Deep Water upwelling areas within the Antarctic Circumpolar Current (ACC), and High Salinity Shelf Waters or temperature/salinity gradients under the winter pack ice in the Indian and Pacific Ocean Sectors appeared to be the most profitable for the elephant seals (Fig. 1, [6]). South Georgia seals favoured relatively close feeding grounds in the Southern Ocean frontal systems, whereas Kerguelen and Macquarie seals preferred most distant locations close to the Antarctic continental shelf. The stronger dependence on sea ice of the latter group, combined with climatological changes in ice extent (that declined in the 1970's), could explain the contrasting abundance trends observed in the populations [6].
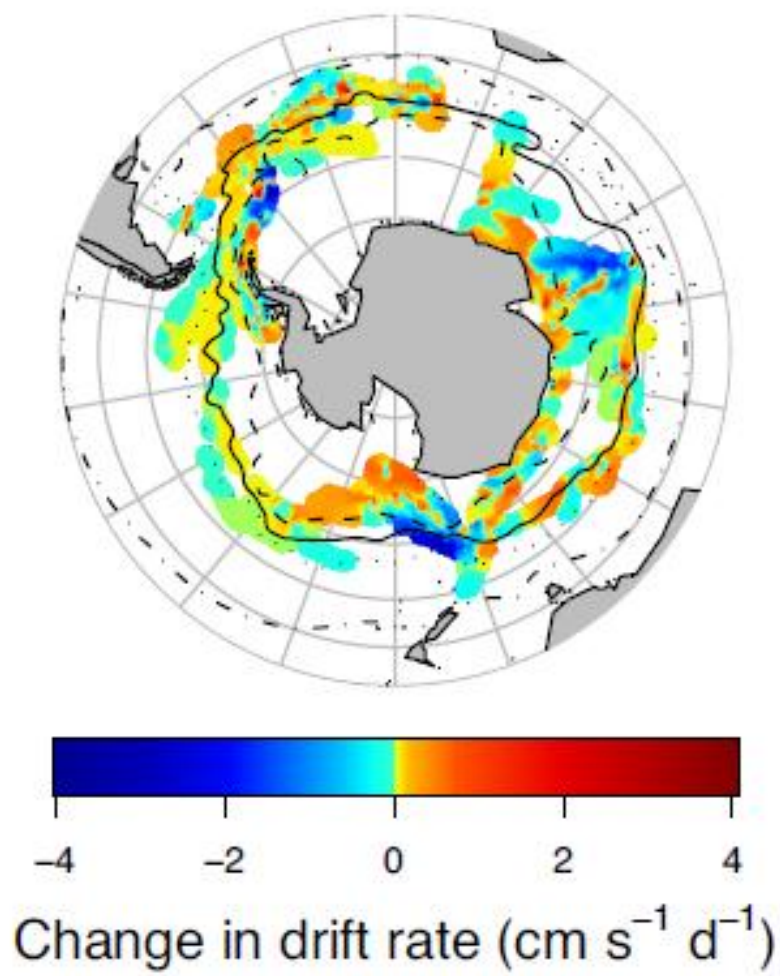

Figure 1. Circumpolar map of physiological changes during winter migrations of elephant seals. Daily change in drift rate was calculated for 36 individuals during their winter migrations in 2004 and 2005. Blue shading represents a

decrease in vertical change in depth during passive drifts, indicating reduced relative lipid content, whereas green-red shading indicates increased vertical depth change and increasing relative lipid content (after [6]).

\section{FORAGING ECOLOGY OF ELEPHANT SEALS AT KERGUELEN ISLAND}

Deployments for the French component of the SEaOS programme took place on the Kerguelen Islands, where one of the largest elephant seal populations in the Southern Ocean is located. Over a 4-year period, we investigated the foraging behaviour of 46 post-moult individuals and their relationships with the physical environment. Using CTD-SRDL and stable isotopes, we examined distribution, diving behaviour, foraging habitats, trophic levels and dietary habits of elephant seals according to their sex and age. Juvenile males foraged over the Kerguelen-Heard Plateau and over the Antarctic shelf, while females foraged mainly in oceanic waters of the Polar Frontal Zone (PFZ) and in Antarctic Waters (Fig. 2). When animals were located close to Antarctic continent, they generally performed benthic foraging dives. However, as the ice expanded during winter females appeared to shift from benthic to pelagic foraging as they shifted farther north, while males continued to forage almost exclusively benthically and remained on the continental shelf [7]. Within the PFZ, mesoscale eddies are known to exert significant 
influence on biological productivity and are expected to provide foraging opportunities for marine predators. In our study, we showed that mesoscale activity clearly influenced the behaviour of individuals. Generally speaking, seals exploited the edge and core of highly turbulent cyclonic eddies to forage [8]. To explore foraging behaviour in more detail, we included the vertical dimension in our analyses to characterize feeding habitats in relation to water masses in a 3-D perspective. Along the Antarctic continent some seals targeted colder waters on the sea bed during benthic dives [9], while within the PFZ, they regularly reached depths below or close to the lower border of cold water's core of cyclonic eddies, which were generally located between 200 and $400 \mathrm{~m}$ [8]). The vertical dimension proved to be crucial in characterizing the behaviour of diving animals accurately. Indeed, while sinuous tracks at the surface could be interpreted as reflecting foraging behaviour, an analysis at depth shows instead that many seals were actually trapped in a restricted area by environmental conditions, such as a high sea ice concentrations, and were not necessarily actively choosing these areas for foraging activities [10]. In addition to these results, we also highlighted the ontogeny of the niche partitioning process in this sexually dimorphic species. While females did not exhibit major dietary shift in relation to their age and their breeding status, a different picture emerged for males. Young males fed at a trophic level identical to that of females. However, when males reached 3 to 4 years of age, they showed a progressive shift upward in trophic level [11]. Thus, the combination of the stable isotope method with the satellite tracking data provides the first evidence of a spatial and trophic shift occurring in this elephant seals population. Moreover, physical data directly recorded at depth by the seals were critical for generating a better understanding of interactions between physical structures and the behaviour of these diving predators. The new generation of data-loggers deployed on seals recording fluorescence at depth along with temperature and salinity is expected to allow an even more in depth analysis of the biotic environment in which the seals forage (see below $\S 7$ ).

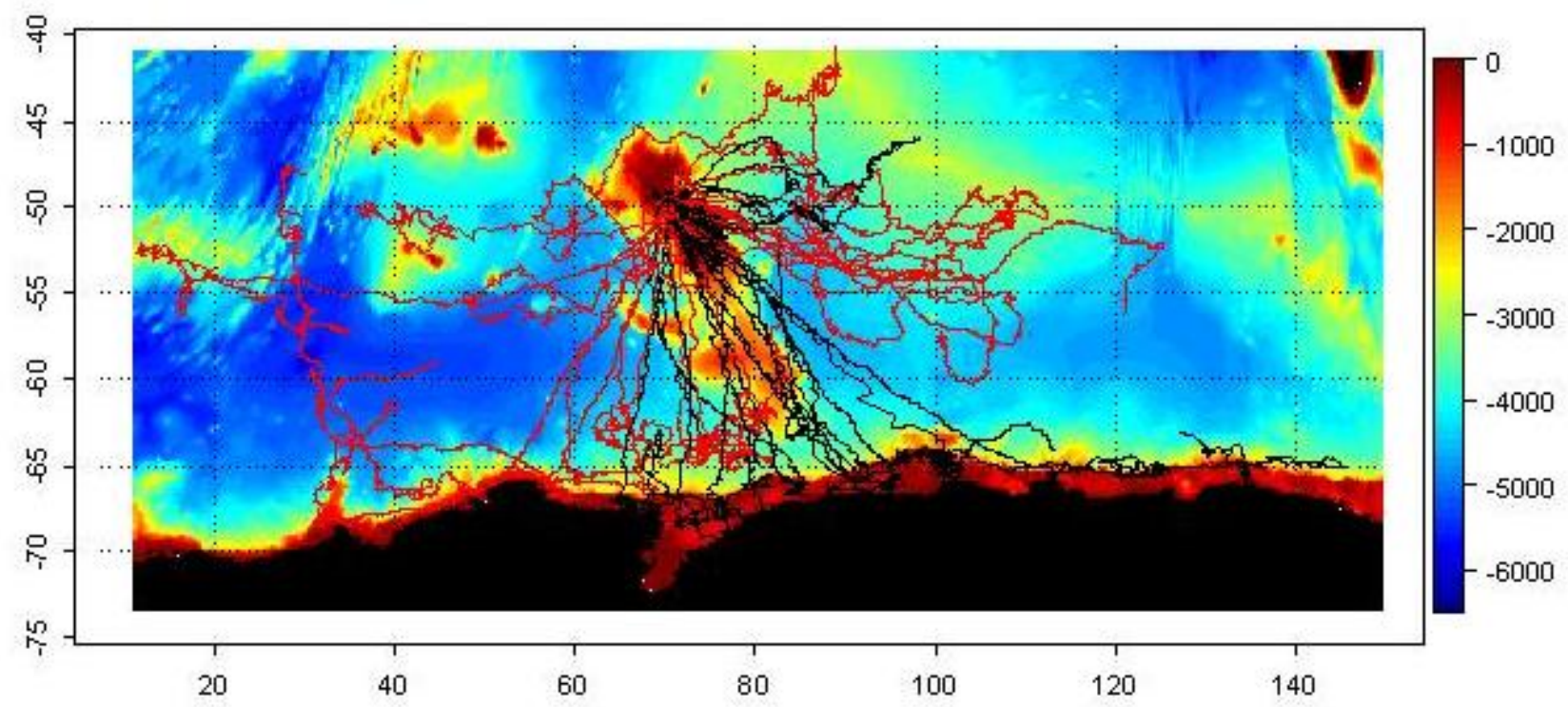

Figure 2. Foraging trips of 46 Kerguelen elephants seals instrumented with CTD-SRDL during 2003/2007. Red tracks indicate females, which mainly explored the Frontal zone of the ACC: black tracks indicate male elephant seals that mainly foraged over the Kerguelen Plateau, and over the Antarctic continental shelf (after [11]).

\section{USING SEALS TO STUDY GLOBAL OCEAN PROCESSES}

Knowledge of ocean processes in the Southern Ocean is generally hampered by the paucity of in situ data, especially at high latitudes [12]. When feeding in winter over the peri-Antarctic shelf or in frontal regions of the open ocean, foraging elephant seals explore vast expanses of the Southern Ocean [6]). Reference [13] showed that temperature and salinity profiles collected by elephant seals in 2004-2005 south of $60^{\circ} \mathrm{S}$ increased by a factor of nine the number of profiles collected by conventional ocean sampling methods in that region over the same period of time. The profiles were highly complementary to the data collected by ship and floats, particularly in the Southern Indian Ocean, along the Antarctic Peninsula and north of the Ross Sea. Reference [14] showed that multiple ocean fronts can be mapped with high temporal and spatial resolution using satellite altimetry. However, this method does not work 
beneath sea-ice, and therefore only limited portions of the circumpolar path of high latitude fronts (such as the southern branch of the SACCF (Southern ACC Front) and the southern boundary of the ACC) can be mapped using altimetry. We used the tight relationship between temperature at $500 \mathrm{~m}$ collected by the seals and sea surface height [14] to extend the maps of the southernmost fronts deep into ice-covered areas. Combined with conventional data, the seal data offered a quasi synoptic, circumpolar view of high latitude fronts within the Southern Ocean, therefore increasing our knowledge of this otherwise poorly sampled region [13].

\section{REGIONAL OCEANOGRAPHIC STUDIES IN OPEN OCEAN}

\subsection{The Kerguelen Plateau, Southern Indian Ocean}

The meridionally-oriented Kerguelen Plateau, which lies right in the middle of the Southern Indian Ocean, is a major barrier that constrains the pathways of the ACC flow. Yet, a lack of data has limited our understanding of the fraction of the ACC transport that crosses the Kerguelen Plateau. In March 2004, 8 instrumented elephant seals from Kerguelen Is. headed rapidly towards the Antarctic shelf after leaving their colony at the end of their moulting period. The remarkable fanshaped distribution of these quasi-simultaneous hydrographic sections combined with their high alongtrack resolution $(\sim 25 \mathrm{~km})$ provided us with a unique opportunity to construct a synoptic view of the circulation over the entire Kerguelen Plateau (Fig. 3). These sections revealed unprecedented details of a strong north-eastward current flowing over the Fawn Trough, a deep passage $(2600 \mathrm{~m})$ across the Kerguelen Plateau. Using these data, [3] showed how the Fawn Trough acts as a bottleneck, channelling most of Antarctic Water found south of the Polar Front into a tightly concentrated and deep-reaching current. These authors also demonstrated that downstream from the Fawn Trough, the Deep Western Boundary Current, which carries cold Antarctic water along the eastern flank of the Southern Kerguelen Plateau, collides with the Fawn Trough Current. To determine the origin of water flowing across the Fawn Trough, different supplementary data were analysed, revealing a complex circulation pattern in the entire Enderby Basin that is strongly controlled by the complex local topography. In this newly emerged frontal scheme, the Fawn Trough appears to be a major convergence zone in the Southern Indian Ocean, that concentrates an important proportion of the ACC flow (25-30\% of ACC transport; [3]).

\subsection{South Atlantic}

References [15 and 16] showed the usefulness of data collected by elephant seals from South-Georgia and South Shetland Is. to study the upper ocean variability in the Scottia Sea. Reference [16] used an empirical relationship between upper ocean temperature and baroclinic mass transport to determine the transport through Drake Passage and compared the derived transport estimates with estimates derived using other techniques. The mean total baroclinic transports in June 2004 and April 2005 were estimated to be $124 \pm 14$ Sv and $112 \pm 14 \mathrm{~Sv}$ respectively. Reference [16] also calculated an absolute geostrophic velocity section across Drake Passage by combining CTD-SRDL data and data of absolute geostrophic surface velocities from altimetry. The complementary nature of animal-borne sensor data to data collected using other ocean observation approaches and how they can produce synergies when integrated is especially highlighted by [15]. In this paper, the large-scale features of the ACC are described in the Atlantic part of the Southern Ocean by merging Argo data and data obtained by animalborne CTD sensors. The merged data set yields unified, gridded hydrogaphic fields with high temporal and spatial resolution, enabling the determination of features absent in each of the data sets separately. The structure and variability of the frontal field of the ACC revealed by this combined data set were compared with those in daily quarter-degree, optimally interpolated sea surface temperature fields and fields of weekly gridded sea level anomaly. In general, the frontal positions were in agreement with previous work, but the improved temporal and spatial resolution provided by the animalborne sensors, revealed some novel features. All frontal positions in the years 2004 and 2005 were more variable than previously indicated across the Scotia Sea and west of the Mid-Atlantic Ridge on seasonal time scales. The merged data set also shows the temporal variability of the Southern ACC Front (SACCF) north of South Georgia and in its position east of the island, where the SACCF lies further north than has been suggested in previous work. In addition, the Subantarctic Front crosses the Mid-Atlantic Ridge about $400 \mathrm{~km}$ further north when compared to previous work. 


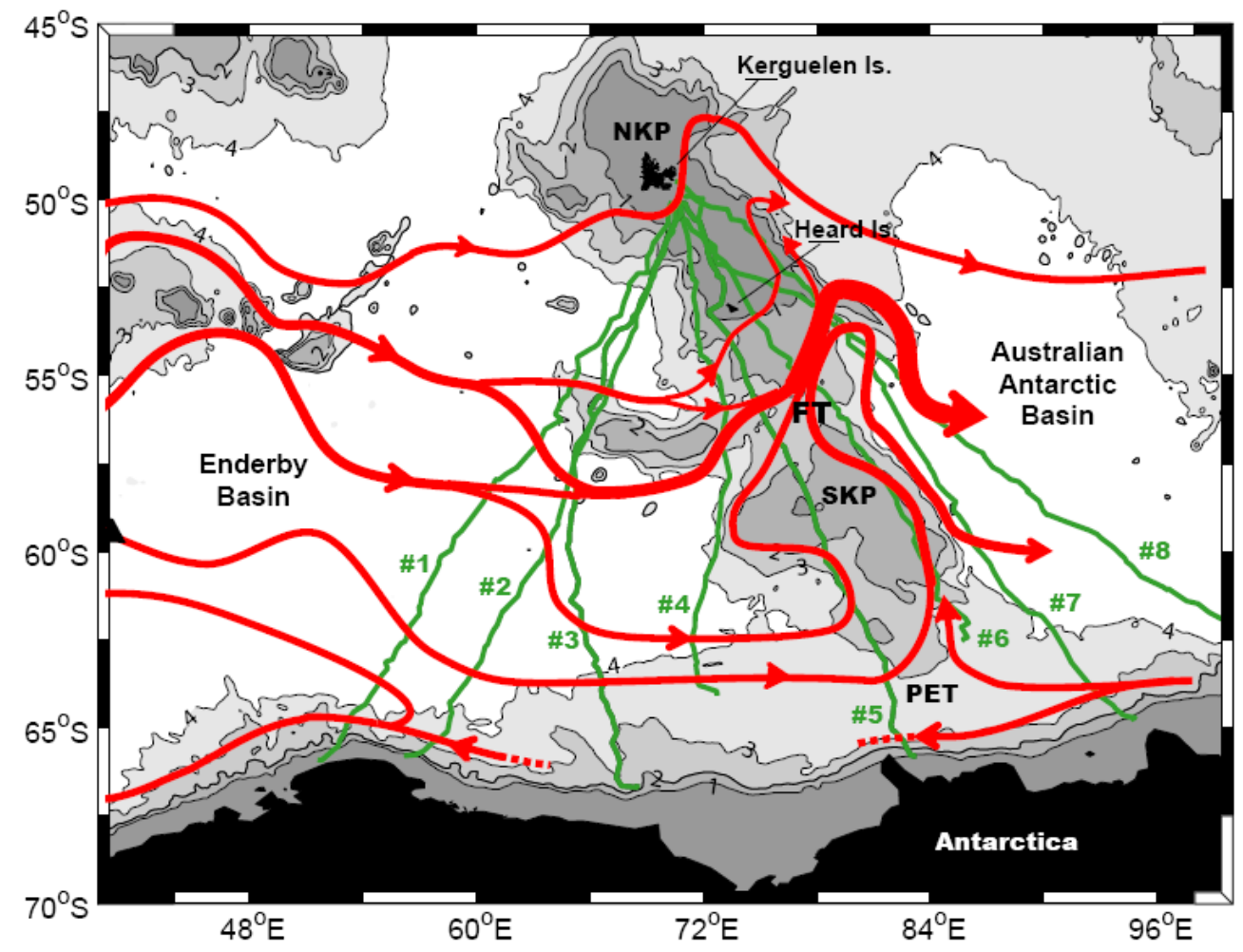

Figure 3. Trajectories of 8 instrumented elephant seals (green lines) from Kerguelen Island. Major topographic features are indicated: the northern Kerguelen Plateau (NKP), southern Kerguelen Plateau (SKP), Fawn Trough (FT) and the Princess Elizabeth Trough (PET). The different pathways of the large-scale circulation, as determined by Roquet et al. (2009), are overlaid in red, showing the channeling of most Enderby Basin water masses across the Fawn Trough (after [3]).

\section{REGIONAL OCEANOGRAPHIC STUDIES IN ICE-COVERED AREAS: EAST ANTARCTIC CONTINENTAL SHELF, ANTARCTIC PENINSULA AND THE WEDDELL SEA}

Along with their ability to sample frontal regions of the Southern Ocean with high spatial and temporal resolution, (see above), an interesting feature of elephant seals' foraging behaviour is their propensity to spend long time periods in high latitude, ice-covered regions during winter. In a number of instances seals remained for period of time in relatively restricted areas within the pack-ice, thereby providing eulerian time series of temperature and salinity from the ice covered water column. The sampling of ice-covered regions in winter by conventional mean is difficult; ice breaker are expensive and slow, Argo floats do not yet operate routinely in sea ice, and moorings can be destroyed by drifting icebergs. Seal-collected data are therefore highly valuable for monitoring the evolution of wintertime ocean properties beneath sea ice. During formation of sea ice, brine is rejected in the water column. Assuming that the resulting salinity increase is only driven by local sea-ice production, changes in salinity in the mixed layer can be used to estimate sea ice formation rates [13 and 17]. Such calculations assume no contribution from horizontal advection, from entrainment from below, or from precipitation and evaporation. Using this approach, [13] calculated the sea ice formation rates from four seals' salinity time-series that stayed 3-14 weeks at four sites over the eastern Antarctic Continental Shelf $\left(65^{\circ}-68^{\circ} \mathrm{S}\right.$, $34^{\circ}-103^{\circ} \mathrm{E}$ ), providing unique estimates for the generic pack ice ( $80 \%$ sea ice concentration). Such data from pack ice are highly complementary to the more precise estimates of sea-ice production in coastal polynyas and in the fast-ice. Sea ice production followed a strong seasonal pattern, peaking in early winter $(\sim 3 \mathrm{~cm} / \mathrm{d}$ in April-May) and decreasing later in the season $(\sim 1 \mathrm{~cm} / \mathrm{d}$ in July-August). A comparison with freezing rate estimates from a Finite-Element Sea Ice-Ocean Model [18] showed good agreement between observed (seal data) and estimated sea ice formation rates ([13]; Fig. 4). Reference [17] studied a winter temperature and salinity time series collected by an elephant seal that foraged for several months close to Signy Island 


\section{Sea-ice net freezing rates}

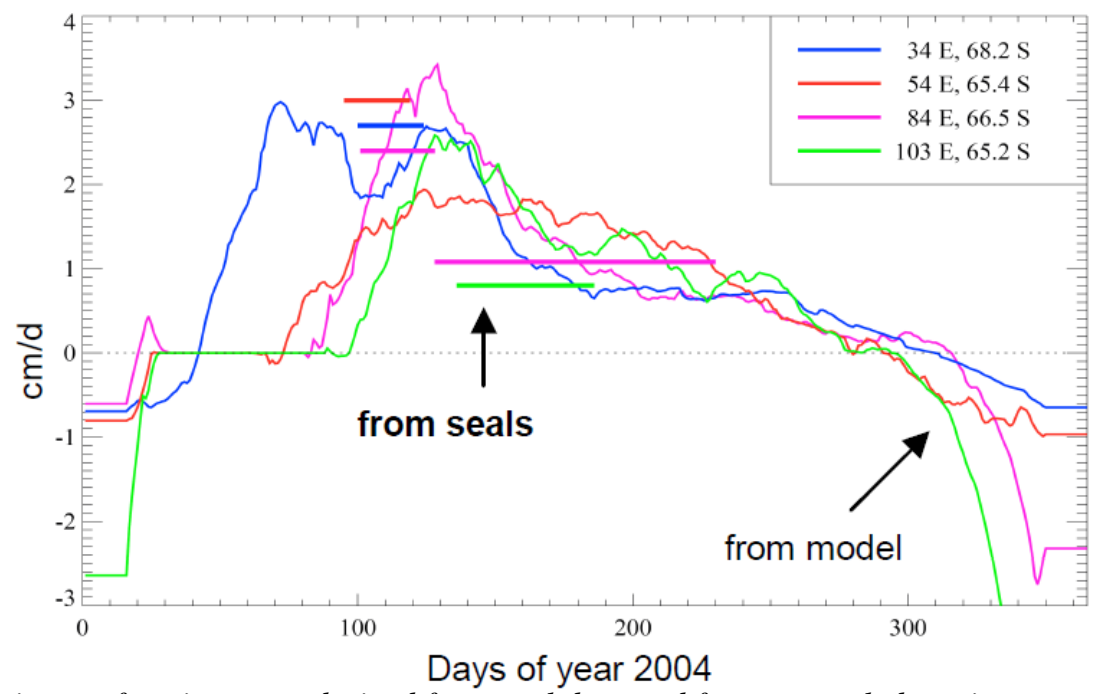

Figure 4. Sea-ice net freezing rates derived from seal data and from a coupled sea ice-ocean model (FESOM)

(Timmermann et al. 2006). Thin lines indicate daily net freezing rates from the model, extracted at four grid points

closest to the respective seal positions and smoothed with a 31-d running mean. Thick horizontal line segments correspond to sea-ice formation rates inferred from the salinity budgets measured by seal $1,2,3$, and 4 at $34^{\circ} \mathrm{E}, 54^{\circ} \mathrm{E}$, $84^{\circ} \mathrm{E}$, and $103^{\circ} \mathrm{E}$, respectively. Length of segment indicates the averaging interval (after [13]).

$\left(60^{\circ} 43^{\prime} \mathrm{S}, 45^{\circ} 36^{\prime} \mathrm{W}\right)$, located at the northern limit of the seasonal sea-ice extension (see [1], this volume).

Using local, one-dimensional ice production modelling and mixed-layer modelling, they showed that the evolution of upper layer salinity in this locality (as measured by the seal tag) is more likely to reflect seaice production rates occurring at higher latitude in the Weddell Sea, rather than the local freezing rates. Not surprisingly, this study contrasts with the results obtained closer to the Antarctic continent by [13]. Unlike the later study, the work by [17] illustrates the case where horizontal advection transfers the salinity signature of sea ice formation occurring at higher latitudes along the coast to lower latitudes. Elephant seal derived data were also used to better understand the hydrography in the vicinity of the Wilkins Ice Shelf (WIS), which experienced several large break-up events in 2008. The maximum depths recorded for the seals led to the discovery of several deep troughs that extend from the outer to the inner continental shelf near the WIS. These troughs provide conduits for the acrossshelf movement of warm $\left(>1^{\circ} \mathrm{C}\right)$ Upper Circumpolar Deep Water (UCDW) (also identified from the seal temperature profiles) and for transport of water at all depths across the ice-shelf front. These data suggest that the thinning of the WIS during the two decades prior to the 2008 break-up events may be explained by a reduction in summer sea-ice distribution leading to increased solar heating of the upper ocean [19]. Work with seal species other than southern elephant seals (Weddell and crabeater seals) is also providing new insights into physical oceanographic processes. For example, data obtained from crabeater seals were used to describe changes in temperature structure, heat content, and heat flux in the upper ocean waters of the Western Antarctic Peninsula (WAP) continental shelf [20].These seal-derived data documented the fall-towinter transition of the surface waters and the shelfwide presence of modified Circumpolar Deep Water (CDW) below 150-200m on the WAP continental shelf. The heat content of the upper $200 \mathrm{~m}$ calculated from the seal-derived temperature profiles ranged between 1000 and $1500 \mathrm{MJm}^{2}$. The seal-derived temperature measurements provided broader spatial and temporal resolution than was possible using any other method. Finally, temperature and salinity data recovered from an instrumented Weddell seal foraging in the central southern Weddell Sea continental shelf documented the poorly known circulation in this region [21]. The lagrangian, vertical, sections of temperature and salinity showed a full depth flow of Modified Warm Deep Water onto the shelf via a sill at the shelf break that accounted for most of the water draining from the Southern Weddell Sea Continental Shelf. Such a data set is truly unique in that it has never been possible to study the wintertime ocean process over this area before this seal-based survey. 


\section{A NEW TYPE OF SENSOR, THE FLUOROMETER}

Polar marine ecosystems are experiencing the greatest rates of change due to global warming on the planet [22]. High latitude marine ecosystems, despite their lower surface area compared to tropical ones, contribute more than $75 \%$ of the global ocean primary production, with the Southern Ocean (SO) contributing the most [23]. Photosynthesis by oceanic phytoplankton is a vital link between organic and inorganic stocks of carbon [24 and 25]. Without this process, the amount of carbon dioxide in the atmosphere would be much higher. Daily, more than a hundred million tons of carbon is fixed into organic material by phytoplankton. However, our understanding of variability in primary production in the Southern Ocean is hampered by the lack of in situ observations, and large-scale surveys using in situ optical measurements are urgently required. They are limitations of satellite assessment of primary production within the different Southern Ocean subsystems. Satellites scan the sea surface, while deep fluorescence maxima are usually found between 40 and $75 \mathrm{~m}$ within the frontal zone of the ACC [26] or in the vicinity of the ice edge [27]. Primary production associated with receding sea-ice cannot normally be properly assessed using satellite observations due to persistent cloud cover and fragmented sea-ice that preclude satellite detection of ephemeral phytoplankton blooms [28 and 29]. A better description of spatial (horizontal and vertical) and temporal (seasonal, inter-annual) distribution of phytoplankton is therefore essential to understand how primary production within the Southern Ocean responds to climate variability, and to assess its sensitivity and vulnerability to ongoing changes. The development of a new generation of SRDL including, for the first time, a fluorescence sensor in addition to the temperature, salinity and pressure sensors was developed by the SMRU in collaboration with the CEBC-CNRS (Centre d'Études Biologiques de Chizé-Centre National de la Recherche Scientifique). This new tag was deployed on elephant seals at Kerguelen Island and allowed collection of a large number of temperature, salinity, and fluorescence profiles over their main foraging grounds, i.e. the most productive sub-systems of the Southern Ocean: the ACC frontal and sea-ice zones, and the Kerguelen-Heard Shelf [6, 7 and 9]. The results provided the first synoptic view of the three dimensional distribution of temperature, salinity and now fluorescence over a vast sector of the Southern Indian
Ocean (Fig. 5; Guinet et al. in prep.). The data allowed the description of the vertical and spatial variation in chlorophyll distribution in relation to the surface mixed layer, but also the description of oceanographic features such as eddies and filaments. The data also showed the occurrence of numerous areas characterized by deep fluorescence maxima that are undetectable from satellite pictures, with fluorescence concentration of up to 5 times the values observed at the surface. These data in association with satellite images of chlorophyll-a concentration will provide three dimensional maps of the distribution of fluorescence, with which to model chlorophyll-a concentrations as well as seasonal and spatial variations in primary production. Special emphasis will be put on the ACC frontal zone and the marginal ice zone in the Indian sector of the Southern Ocean utilized by females elephant seals, as well as on the shelf areas visited by the males. This new approach should help us to understand how primary production varies with climate and physical ocean anomalies.

\section{FUTURE DEVELOPMENTS}

With regards the use of marine mammals as biosamplers of oceanographic features the choice of the measured variables has been initially guided by their ability to characterize oceanographic features, by the energy consumption associated with the measurement of those variables and by the available technology. There is also currently a strong constraint on the amount of data that can be transmitted in near real time through the Argos system due to the limited message size and amount of time spent at the surface between dives; this has direct consequence on the quantity of acquired parameters. At this stage, the limit appears to be reached with 4 parameters (pressure, temperature, salinity and one other parameter) and a compromise has to be set between the numbers of parameters collected and their sampling rate. The more parameters the lower should be the sampling frequency if we do not want to compromise the life expectancy of the tags. By using the tag as a logger to store the collected data rather than transmitting them via satellite, more parameters could be recorded. This would however really only be an option for parameters that are energetically very cheap to measure, such as light transmittance, and when there is a good chance of recovering the equipment based on the animal behaviour (differed mode). 
Technology is continuously evolving and there are now commercially available miniaturized instruments that can measure a large set of biogeochemical parameters (e.g. chlorophyll concentration, dissolved oxygen concentration, backscattering, colored dissolved organic matter (CDOM) concentration, underwater light transmittance). As technological advancements continue in the fields of miniaturization, energetic power and transmission, a wider range of available parameters that can be recorded with a SRDL will be possible. Justification for the measured parameters must be based on scientific relevance, in that its evaluation should always add an important piece of information on the knowledge of the marine ecosystem functioning, Selection of the sampled parameters also depends on the nature of the experiment, such as long-term, basin-scale monitoring or regional, shorter time scale observations.Furthermore, when considering SRDL sensors, the choice of the parameters should in addition to collecting relevant physical and biogeochemical data for the oceanographers afford a better understanding of the at-sea ecology of the tagged animal in relation to oceanographic features, as it is unethical to deploy tags on animals solely to collect oceanographic parameters.

As part of the French PABIM (Autonomous Platforms in Biogeochemistery : Instrumentation and Measures) work group and white book, four criteria, which should be considered as a starting point for further discussion, were set to define a core parameter:

1. A core parameter should be a robust proxy of a biogeochemical oceanic process or variable.
2. The measurement of a core parameter with an autonomous platform should be cost effective and low in energy consumption.

3. A core parameter should have already been measured extensively and for a long time with referenced methods.

4. A core parameter obtained from autonomous platforms should be easily comparable with observations collected with classical methods (i.e. ships, satellites, moorings). If climatologies are produced from previous observations, data from autonomous floats should be easily incorporated.

The last two points, in particular, are at present the most limiting. Only temperature, salinity and chlorophyll are routinely measured by CTD-SRDL. The integration of an oxygen sensor (instead of a fluorometer) is currently in progress, which will further both biological and physical oceanographic understanding. In terms of elephant seal ecology, it will allow us to assess if Southern elephant seals target the minimum oxygen layer to forage efficiently on their prey. Dissolved oxygen concentration (DO hereafter) is a key parameter in understanding both dynamics and biogeochemistry of the world oceans, through its use as a water mass tracer and in quantifying mixing rates. It is also associated with many biological processes, production, respiration and remineralization. One pressing scientific question is how current global climate change could affect these dynamic and biological processes in the long term. Several studies, based on shipboard DO measurements or on the sparse existing repeat sampling locations, have already provided some insight into this, and stress the importance of obtaining long term, global DO data. 

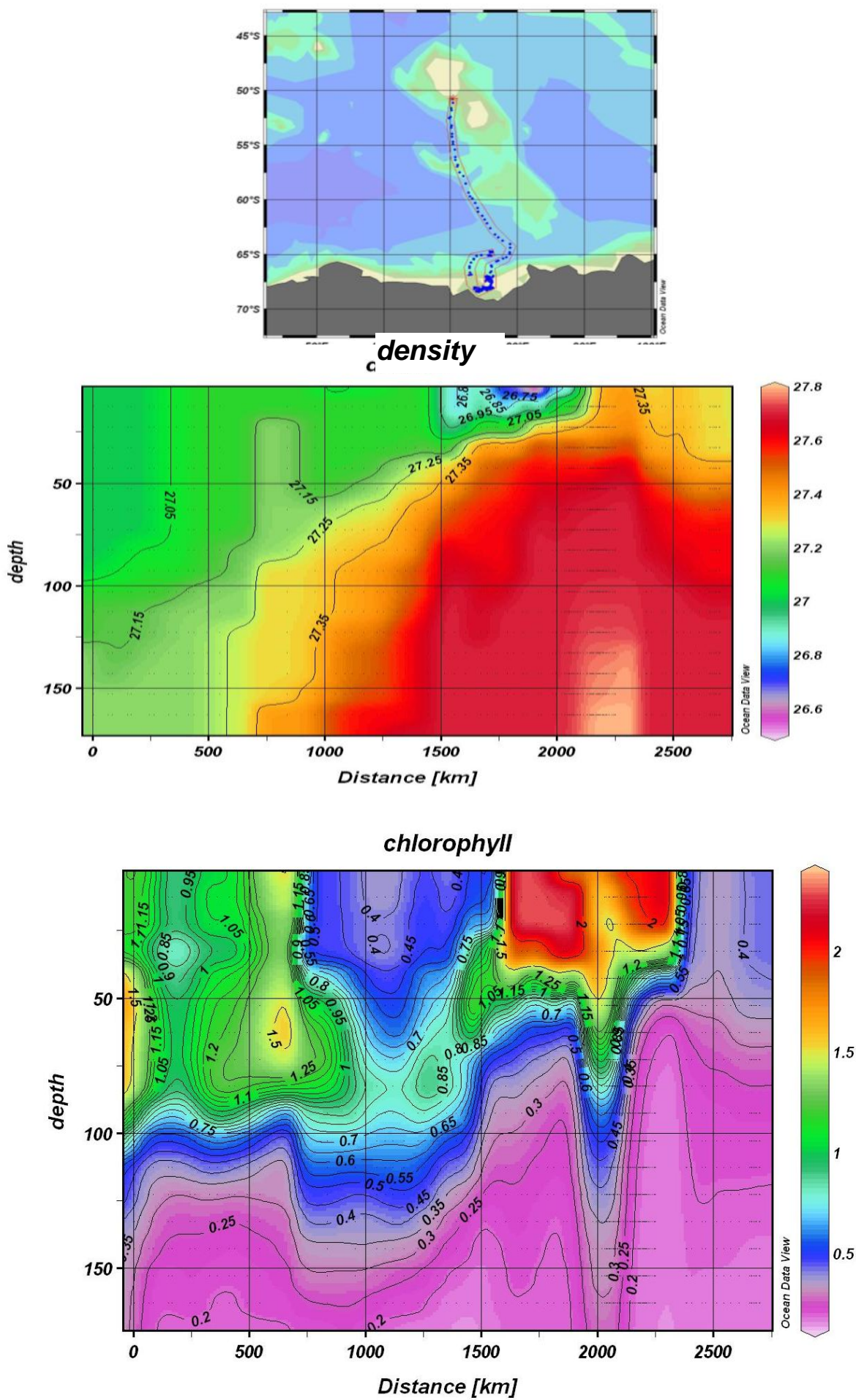

Figure 5. Novel data collected by an elephant seal equipped with a new generation SMRU CTD-Fluorescence tag developed in collaboration with the CEBC-CNRS. This elephant seal travelled from Kerguelen Island to Antarctica in January 2009 sampling chlorophyll-a concentration $(\mu \mathrm{g} / \mathrm{l})$ for the top $180 \mathrm{~m}$ (euphotic layer) while temperature and salinity are sampled over the whole diving depth. Temperature and salinity are used to calculate the density and the mixed layer thickness which control the vertical distribution of the phytoplankton along this Kerguelen-Antarctic transect (after Guinet et al. in prep) 
Two other parameters, particulate organic carbon (POC) and CDOM, could in the near future meet all four of the listed requirements. However these two parameters are not stand alone parameters and must be obtained in parallel with fluorescence data, clearly a limitation with the current Argos system. We may also hope to be in a position to measure nutrient concentrations in a not too distant future.

The sustainability of animal-based observing systems will depend on the scientific interest of studying marine mammals' at-sea behaviour in the long term. Located at the top of the food webs, marine mammals integrate the different trophic levels and are valuable indicators of the state of the marine ecosystem. Building long time series of both the animals' ecology and ocean parameters is crucial in understanding how the marine ecosystems will respond to climate change, stressing the importance of perpetuating these animalbased observing systems.

\section{REFERENCES}

1. Boehme, L. \& Co-Authors (2010). "Biologging in the Global Ocean Observing System" in these proceedings (Vol. 2), doi:10.5270/OceanObs09.cwp.06.

2. Roquet, F. \& Co-Authors (2010). "On the validation of hydrographic data collected by instrumented elephant seals" in Proceedings of OceanObs'09: Sustained Ocean Observations and Information for Society (Annex), Venice, Italy, 21-25 September 2009, Hall, J., Harrison, D.E. \& Stammer, D., Eds., ESA Publication WPP-306, doi:10.5270/OceanObs09.

3. Roquet, F., Park, Y.H, Guinet, C., Bailleul, F. \& Charrassin, J.B. (2009). Observations of the Fawn Trough Current over the Kerguelen Plateau from instrumented elephant seals. J. Mar. Sys. 78, 377-393.

4. Costa, D., Block, B., Bograd, S., Fedak, M. and Gunn, J., (2010). "TOPP as a Marine Life Observatory: Using Electronic Tags to Monitor the Movements, Behaviour and Habitats of Marine Vertebrates" in these proceedings (Vol. 2), doi:10.5270/OceanObs09.cwp.19.

5. McMahon, C.R, Bester, M.N, Burton, H.R., Hindell, M.A., \& Bradshaw, C.J.A. (2005) Population status, trends and a re-examination of the hypotheses explaining the recent declines of the southern elephant seal Mirounga leonina. Mamm. Rev. 35, 82-100.

6. Biuw, M., Boehme, L., Guinet, C., Hindell, M., Costa, D., Charrassin, J.B., Roquet, F., Bailleul, F., Meredith, M., Thorpe, S, Tremblay, Y, McDonald, B., Park, Y.-H., Rintoul, S., Bindoff, N., Goebel, M., Crocker, D., Lovell, P., Nicholson J., Monks F. \& Fedak, M. (2007). Variations in behaviour and condition of a Southern Ocean top predator in relation to in-situ oceanographic conditions. Proc.Natl. Acad. Sc. USA 104, 13705-13710.

7. Bailleul, F., Charrassin, J-B., Ezraty, R., GirardArdhuin, F., McMahon, C.R., Field I. \& Guinet C. (2007). Southern elephant seals from Kerguelen Islands confronted by Antarctic sea ice. Changes in movements and in diving behaviour. Deep Sea Res II 54, 343-355.

8. Bailleul, F., Cotté, C. \& Guinet C. Details of feeding behaviour of a deep diving predator in the heart of mesoscale eddies revealed by satellite and in-situ data. (submitted)

9. Bailleul, F., Charrassin, J-B., Monestiez, P., Roquet, F., Biuw, M. \& Guinet C. (2007). Successful foraging zones of Southern elephant seals from Kerguelen Islands in relation to oceanographic conditions. Phil. Trans. Roy. Soc. B 362, 2169-2181.

10. Bailleul, F., Pinaud, D., Hindell, M., Charrassin, J-B. \& Guinet, C. (2008). Assessment of scale-dependent foraging behaviour in Southern elephant seals incorporating the vertical dimension: a development of the First Passage Time method. J. Anim. Ecol. 77, 948-957.

11. Bailleul, F., Authier, M., Ducatez, S., Roquet, F., Charrassin, J.-B., Cherel, Y. and Guinet, C. (2010), Looking at the unseen: combining animal bio-logging and stable isotopes to reveal a shift in the ecological niche of a deep diving predator. Ecography, 33: 709719. doi:10.1111/j.1600-0587.2009.06034.x

12. Rintoul, S., Church, J., Fahrbach, E., Garcia, M., Gordon, A., King, B., Morrow, R., Orsi, A.H., \& Speer, K. (2001). Monitoring and Understanding Southern Ocean Variability and its Impact on Climate: A Strategy for Sustained Observations. Observing the Oceans in the 21st Century, C.J. Koblinsky and N.R. Smith (Eds), GODAE Project Office and Bureau of Meteorology, Melbourne.

13. Charrassin, J.-B., Hindell, M., Rintoul, S.R., Roquet, F., Sokolov, S., Biuw, M., Costa, D., Boehme, L., Lovell, P., Coleman, R., Timmerman, R., Meijers, A., Meredith, M., Park, Y.-H., Bailleul, F., Goebel, M., Tremblay, Y., Bost, C.-A., McMahon, C.R., Field, I.C., Fedak, M.A., \& Guinet C. (2008). Southern Ocean frontal structure and sea ice formation rates revealed by elephant seals. Proc.Natl. Acad. Sc. USA 105, 11634-11639.

14. Sokolov, S. \& Rintoul S.R. (2007). Multiple jets of the Antarctic Circumpolar Current south of Australia. $J$. Phys. Oceanogr. 37, 1394-1412.

15. Boehme, L., Meredith, M.P., Thorpe, S.E., Biuw, M., \& Fedak M. (2008). Antarctic Circumpolar Current frontal system in the South Atlantic: Monitoring using merged Argo and animal-borne sensor data. J. Geoph. Res. 113, C09012, doi:10.1029/2007JC004647.

16. Boehme, L., Thorpe, S.E., Biuw, M., Fedak, M., \& Meredith, M.P. (2008). Monitoring Drake Passage with elephant seals: Frontal structures and snapshots of transport. Limon. \& Oceanogr. 53, 2350-2360. 
17. Meredith, MP, Nicholls, KW, Renfrew, IA, Boehme, L, Biuw, M and Fedak, M (2011) Seasonal evolution of the upper-ocean adjacent to the South Orkney Islands, Southern Ocean: Results from a "lazy biological mooring". Deep-Sea Research Part II: Tropical Studies in Oceanography. doi:10.1016/j.dsr2.2009.07.008.

18. Timmermann, R., Danilov S., \& Schröter, J.A. (2006) Finite element global coupled sea ice-ocean model. Geophys. Res. Abstr. 8, 07063, SRef-ID: 16077962/gra/EGU06-A-07063.

19. Padman, L., Costa, D.P., Fricker, H.A., Scambos, T., Dinniman, M.S., Goebel, M.E., Humbert, A., \& McDonald, B.(2009). Pre-collapse thinning of Wilkins Ice Shelf, Antarctica by basal melting. Earth and Planetary Science Letters, Volume 280, Issues 14, 15 April 2009, Pages 51-60

20. Costa, D.P., Klinck, J.M., Hofmann, E.E., Dinniman, M.S., \& Burns, J.M. (2008). Upper ocean variability in West Antarctic Peninsula continental shelf waters as measured using instrumented seals. Deep Sea Res.II. 55, 323-337.

21. Nicholls, K.W., Boehme, L., Biuw, M., \& Fedak M.A. (2008). Wintertime ocean conditions over the southern Weddell Sea continental shelf, Antarctica, Geophys. Res. Let. 35, L21605, doi:10.1029/2008GL035742.

22. IPCC, 2007: Climate Change 2007: The Physical Science Basis. Contribution of Working Group I to the Fourth Assessment Report of the Intergovernmental Panel on Climate Change. Solomon, S., Qin, D., Manning, M., Chen, Z., Marquis, M., Averyt, K.B., Tignor, M. \& Miller H.L. (Eds.). Cambridge University Press, Cambridge, United Kingdom and New York, NY, USA, 996 pp.

23. Sarmiento, J. L., Gruber, N., Brzezinski, M. A. \& Dunne, J.P. (2004). High-latitude controls of thermocline nutrients and low latitude biological productivity. Nature 427, 56-60.

24. Field, C.B., Behrenfeld, M.J., Randerson, J.T. \& Falkowski, P.G. (1998). Primary production of the biosphere: Integrating terrestrial and oceanic components. Science 281, 237-240.

25. Behrenfeld, M.J., Randerson, J.T., McClain, C.R., Feldman, G.C., Los, S.O., Tucker, C.J., Falkowski, P.G., Field, C.B., Frouin, F., Esaias, W.E., Kolber, D.D. \& Pollack, N.H. (2001). Biospheric primary production during an ENSO transition. Science 291, 2594-2597.

26. Quéguiner, B., \& Brzezinsky, M. (2002). Biogenic silica production rates and particulate organic matter distribution in the Atlantic sector of the Southern Ocean, during Austral spring 1992. Deep Sea Res. II 49, 1765-1786

27. Waite, A.M., \& Nodder, S.D. (2001). The effect of in situ iron addition on the sinking rate and export flux of Southern Ocean Diatoms. Deep Sea Res. II 48, 2635-2654.
28. Arrigo, K. R., Worthen, D. L., Lizotte, M. P., Dixon, P. \& Dieckman, C. (1997). Primary production in Antarctic sea-ice. Science 276, 394-397.

29. Buesseler, K.O., Barber, R.T., Dickson, M.-L., Hiscock, M.R., Moore, J.K. \& Sambrotto, R. (2003). The effect of marginal ice-edge dynamics on production and export in the Southern Ocean along $170^{\circ} \mathrm{W}$. Deep-Sea Res.II 50, 579-603. 